\title{
An ancestral core haplotype defines the critical region harbouring the North Carolina macular dystrophy gene (MCDR1)
}

\author{
C G Sauer, H D Schworm, M Ulbig, A Blankenagel, K Rohrschneider, D Pauleikhoff, \\ T Grimm, B H F Weber
}

\begin{abstract}
Autosomal dominant North Carolina macular dystrophy (NCMD) or central areolar pigment epithelial dystrophy (CAPED) is an allelic disorder that maps to an approximately $7.2 \mathrm{cM}$ interval between DNA markers at D6S424 and D6S1671 on 6q14-q16.2. The further refinement of the disease locus has been hindered by the lack of additional recombination events involving the critical region. In this study, we have identified three multigeneration families of German descent who express the NCMD phenotype. Genotyping was carried out with a series of markers spanning approximately $53 \mathrm{cM}$ around the NCMD locus, MCDR1. Genetic linkage between the markers and the disease phenotype in each of the families could be shown. Disease associated haplotypes were constructed and provide evidence for an ancestral founder for the German NCMD families. This haplotype analysis suggests that a $4.0 \mathrm{cM}$ interval flanked by markers at D6S249 and D6S475 harbours the gene causing NCMD, facilitating further positional cloning approaches.

(F Med Genet 1997;34:961-966)
\end{abstract}

Keywords: NCMD; CAPED; chromosome 6q14q16.2; linkage analysis

Autosomal dominant North Carolina macular dystrophy (NCMD) was first reported as a nosological entity more than 25 years ago.' Particularly in the early stages of the disease, the variable but highly penetrant NCMD phenotype shows striking similarities to age related macular degeneration (AMD), a complex macular disorder with a high prevalence in western countries. As in AMD, small, yellowish drusen may be present in NCMD mainly in the central retina. At this stage, visual acuity is normal or slightly subnormal. In grade 2 NCMD the drusen appear "confluent" and may be accompanied by disciform lesions or the formation of subretinal choroidal neovas- cular membranes. In these cases visual acuity may be impaired. Severe cases of NCMD present with macular colobomas. In general, the disease onset is during infancy and appears to be non-progressive with a median visual acuity between $20 / 40$ and $20 / 60 .^{2}$ Electroretinography (ERG), electro-oculography (EOG), and colour vision are generally normal.

The variable expressivity of the disease gene was further highlighted by recent findings that showed NCMD and a clinically distinct phenotype referred to as central areolar pigment epithelial dystrophy (CAPED) ${ }^{34}$ to occur in separate but genealogically related branches of a single large North Carolina family. ${ }^{5}$ This has led to the conclusion that the two disorders represent a single nosological entity and, therefore, have to be considered allelic.

In an effort to identify the NCMD gene by its chromosomal position, the disease locus, MCDR1, was mapped to chromosome 6q14q16.2 by genetic linkage analysis in a large North Carolina pedigree. ${ }^{2}$ Subsequently, additional NCMD families of various ethnic origins and from different geographical regions were identified and have mapped the MCDR1 locus to an approximately $7.2 \mathrm{cM}$ interval flanked by DNA markers at D6S424 and D6S1671. ${ }^{6}$ So far, there is no clear indication for locus heterogeneity, ${ }^{7}$ with the possible exception of one family of Indian origin where affected subjects present with features simulating NCMD. ${ }^{8}$ Genetic linkage of the disease phenotype in this family to the MCDR1 locus was excluded. Recently, progressive bifocal chorioretinal atrophy (PBCRA) was mapped to an interval overlapping the MCDR1 locus. ${ }^{9}$ The possibility that NCMD and PBCRA are allelic disorders has been discussed, although clarification will have to await the isolation of the MCDR1 gene.

To facilitate the application of positional cloning strategies, alternate approaches are needed to refine the MCDR1 locus. Allelic association studies in combination with disease associated haplotype analyses have previously been used successfully to narrow the location of several important disease genes further..$^{10-12}$ In these studies an increased measure of 
Table 1 Pairwise linkage analysis between NCMD/CAPED and 12 markers from chromosome 6q14-q16.2

\begin{tabular}{|c|c|c|c|c|c|c|c|c|c|}
\hline \multirow[b]{2}{*}{ Marker } & \multicolumn{7}{|c|}{$Z$ at $\theta$ of } & \multirow[b]{2}{*}{$\theta \max$} & \multirow[b]{2}{*}{$Z \max$} \\
\hline & 0 & 0.01 & 0.05 & 0.1 & 0.2 & 0.3 & 0.4 & & \\
\hline \multicolumn{10}{|l|}{ D6S286 } \\
\hline Family L & 2.08 & 2.06 & 1.96 & 1.82 & 1.45 & 0.99 & 0.48 & \multirow{4}{*}{0.15} & \multirow{4}{*}{1.76} \\
\hline Family A & $-\infty$ & -1.65 & -0.40 & 0.02 & 0.23 & 0.16 & 0.05 & & \\
\hline Family W & $-\infty$ & -1.11 & -0.44 & -0.19 & 0.01 & 0.07 & 0.06 & & \\
\hline Total & $-\infty$ & -0.70 & 1.12 & 1.65 & 1.69 & 1.22 & 0.59 & & \\
\hline \multicolumn{10}{|l|}{ D6S252 } \\
\hline Family L & 2.45 & 2.41 & 2.22 & 1.98 & 1.43 & 0.86 & 0.35 & \multirow{4}{*}{0} & \multirow{3}{*}{3.65} \\
\hline Family A & 1.20 & 1.18 & 1.07 & 0.93 & 0.63 & 0.33 & 0.08 & & \\
\hline Family W & 0.00 & 0.00 & 0.00 & 0.00 & 0.00 & 0.00 & 0.00 & & \\
\hline Total & 3.65 & 3.59 & 3.29 & 2.91 & 2.06 & 1.19 & 0.43 & & \\
\hline \multicolumn{10}{|l|}{ D6S300 } \\
\hline Family L & 3.31 & 3.25 & 3.02 & 2.72 & 2.06 & 1.34 & 0.61 & \multirow{4}{*}{0} & \multirow{4}{*}{6.32} \\
\hline Family A & 2.17 & 2.12 & 1.94 & 1.71 & 1.25 & 0.78 & 0.33 & & \\
\hline Family W & 0.84 & 0.82 & 0.77 & 0.70 & 0.55 & 0.38 & 0.19 & & \\
\hline Total & 6.32 & 6.19 & 5.73 & 5.13 & 3.86 & 2.50 & 1.13 & & \\
\hline D6S501 & & & & & & & & & \\
\hline Family L & 1.55 & 1.52 & 1.41 & 1.27 & 0.97 & 0.66 & 0.34 & & \\
\hline Family A & 2.36 & 2.32 & 2.14 & 1.91 & 1.41 & 0.85 & 0.29 & 0 & 4.81 \\
\hline Family W & 0.90 & 0.89 & 0.84 & 0.77 & 0.61 & 0.44 & 0.24 & & \\
\hline Total & 4.81 & 4.73 & 4.39 & 3.95 & 2.99 & 1.95 & 0.87 & & \\
\hline D6S249 & & & & & & & & & \\
\hline Family L & 3.09 & 3.02 & 2.77 & 2.46 & 1.83 & 1.18 & 0.49 & & \\
\hline Family A & 0.33 & 0.32 & 0.28 & 0.23 & 0.14 & 0.07 & 0.02 & 0 & 4.32 \\
\hline Family W & 0.90 & 0.89 & 0.83 & 0.76 & 0.61 & 0.44 & 0.24 & & \\
\hline Total & 4.32 & 4.23 & 3.88 & 3.45 & 2.58 & 1.69 & 0.75 & & \\
\hline D6S1716 & & & & & & & & & \\
\hline Family L & 2.51 & 2.46 & 2.28 & 2.03 & 1.51 & 0.94 & 0.39 & & \\
\hline Family A & 1.54 & 1.51 & 1.40 & 1.25 & 0.94 & 0.61 & 0.29 & 0 & 4.32 \\
\hline Family W & 0.27 & 0.26 & 0.24 & 0.21 & 0.16 & 0.10 & 0.05 & & \\
\hline Total & 4.32 & 4.23 & 3.92 & 3.49 & 2.61 & 1.65 & 0.73 & & \\
\hline D6S1717 & & & & & & & & & \\
\hline Family L & 2.82 & 2.76 & 2.55 & 2.26 & 1.66 & 1.03 & 0.43 & & \\
\hline Family A & 2.30 & 2.27 & 2.14 & 1.95 & 1.52 & 1.01 & 0.44 & 0 & 6.02 \\
\hline Family W & 0.90 & 0.89 & 0.84 & 0.77 & 0.61 & 0.44 & 0.24 & & \\
\hline Total & 6.02 & 5.92 & 5.53 & 4.98 & 3.79 & 2.48 & 1.11 & & \\
\hline D6\$475 & & & & & & & & & \\
\hline Family L & 4.21 & 4.14 & 3.86 & 3.48 & 2.67 & 1.77 & 0.80 & & \\
\hline Family A & 3.31 & 3.25 & 3.02 & 2.72 & 2.05 & 1.31 & 0.54 & 0 & 8.42 \\
\hline Family W & 0.90 & 0.89 & 0.84 & 0.77 & 0.61 & 0.44 & 0.24 & & \\
\hline Total & 8.42 & 8.28 & 7.72 & 6.97 & 5.33 & 3.52 & 1.58 & & \\
\hline D6\$1543 & & & & & & & & & \\
\hline Family L & 3.29 & 3.25 & 3.07 & 2.81 & 2.22 & 1.52 & 0.72 & & \\
\hline Family A & 2.06 & 2.03 & 1.92 & 1.75 & 1.34 & 0.85 & 0.34 & 0 & 6.25 \\
\hline Family W & 0.90 & 0.89 & 0.84 & 0.77 & 0.61 & 0.44 & 0.24 & & \\
\hline Total & 6.25 & 6.17 & 5.83 & 5.33 & 4.17 & 2.81 & 1.30 & & \\
\hline D6S1671 & & & & & & & & & \\
\hline Family L & 2.79 & 2.76 & 2.63 & 2.43 & 1.94 & 1.33 & 0.62 & & \\
\hline Family A & 3.31 & 3.25 & 3.02 & 2.72 & 2.05 & 1.31 & 0.54 & 0 & 7.00 \\
\hline Family W & 0.90 & 0.89 & 0.84 & 0.77 & 0.61 & 0.44 & 0.24 & & \\
\hline Total & 7.00 & 6.90 & 6.49 & 5.92 & 4.60 & 3.08 & 1.40 & & \\
\hline D6S283 & & & & & & & & & \\
\hline Family L & 3.31 & 3.25 & 3.02 & 2.72 & 2.06 & 1.34 & 0.61 & & \\
\hline Family A & 2.74 & 2.69 & 2.47 & 2.19 & 1.60 & 0.98 & 0.39 & 0 & 6.95 \\
\hline Family W & 0.90 & 0.89 & 0.84 & 0.77 & 0.61 & 0.44 & 0.24 & & \\
\hline Total & 6.95 & 6.83 & 6.33 & 5.68 & 4.27 & 2.76 & 1.24 & & \\
\hline D6S262 & & & & & & & & & \\
\hline Family L & $-\infty$ & -1.03 & -0.30 & 0.00 & 0.20 & 0.22 & 0.14 & & \\
\hline Family A & $-\infty$ & -3.87 & -1.64 & -0.73 & -0.02 & 0.20 & 0.18 & 0.34 & 0.37 \\
\hline Family W & $-\infty$ & -1.40 & -0.72 & -0.44 & -0.19 & -0.08 & -0.02 & & \\
\hline Total & $-\infty$ & -6.30 & -2.66 & -1.17 & -0.01 & 0.34 & 0.30 & & \\
\hline
\end{tabular}

non-random allelic association between the polymorphic DNA markers and the disease loci showed ancient founder effects and reliably located the respective disease genes to very small chromosomal regions.

Here, we have ascertained affected and unaffected members from three multigeneration pedigrees of German descent suffering from NCMD that were presumed to be unrelated by pedigree studies. One of these families has previously been reported to resemble more closely the CAPED phenotype. ${ }^{13}$ Extensive genotyping was performed using a series of highly polymorphic DNA markers linked to the MCDR1 locus on chromosome 6q14-q16.2. Our data show that the phenotype in the three families is linked to the MCDR1 locus, lending further support to previous findings of genetic homogeneity in
NCMD and allelism of NCMD and CAPED (table 1$).^{26}$ In addition, we have identified three disease associated haplotypes that partly overlap at several polymorphic DNA loci, suggesting a genealogical link between the German NCMD families. These analyses provide a powerful approach to refining further the locus harbouring MCDR1.

\section{Methods}

PATIENTS

A total of 24 affected and 14 unaffected subjects from three families of German origin were included in the present study (fig 1) and underwent comprehensive ophthalmic examination. The affected people in families L, A, and W presented with fundus abnormalities consistent with NCMD, as described in detail earlier. ${ }^{1256}$ 
Family L

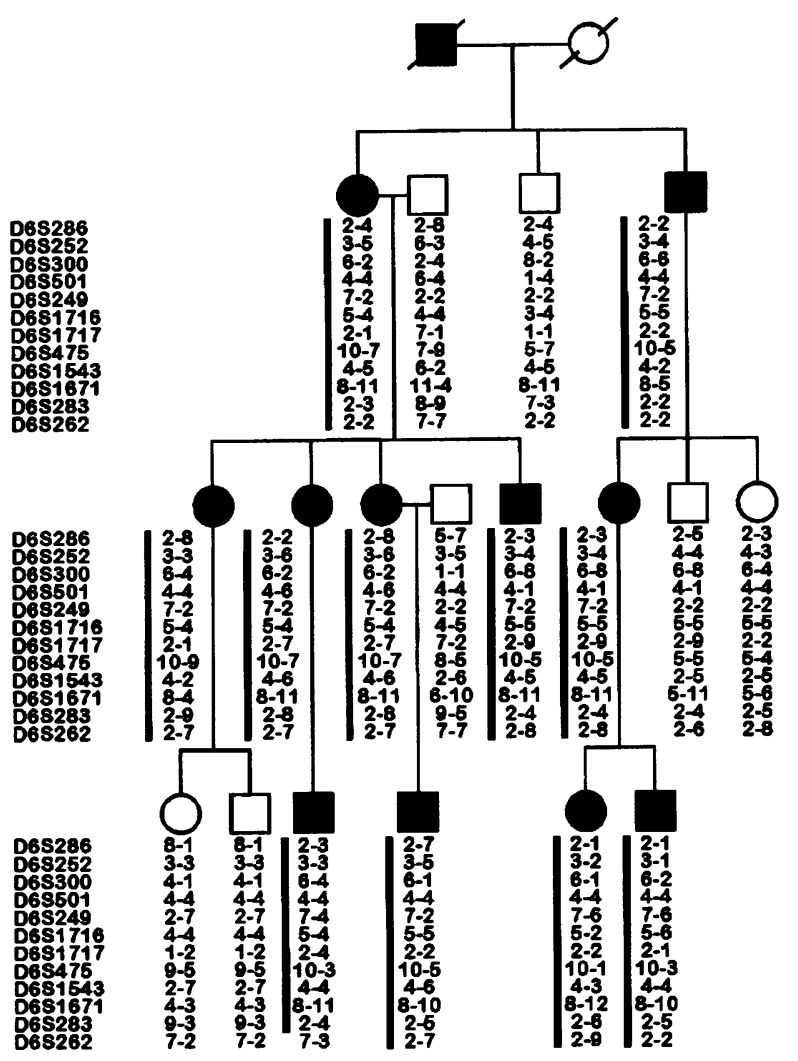

Family A

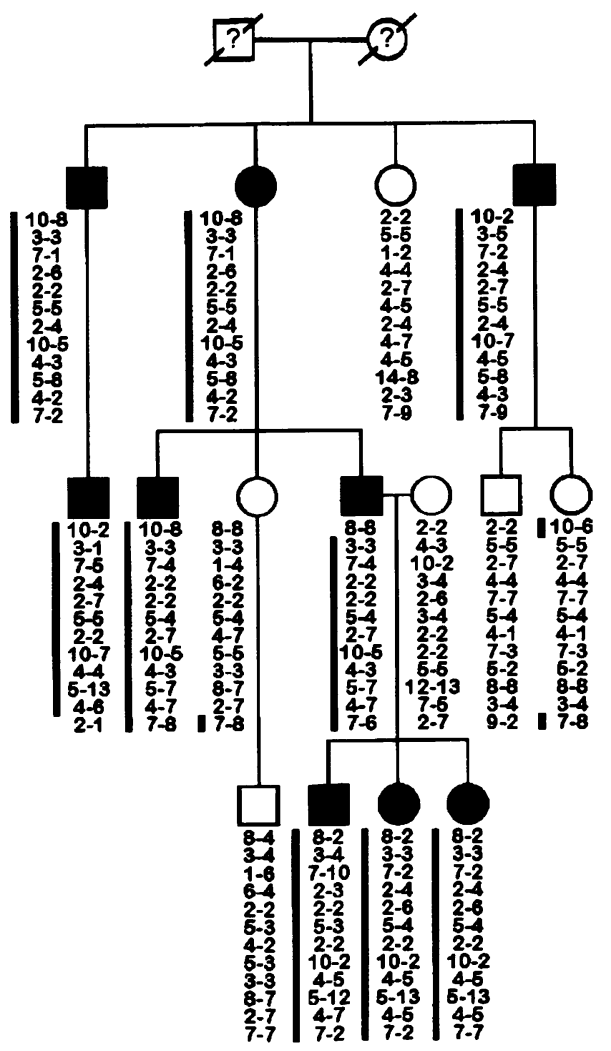

Family W

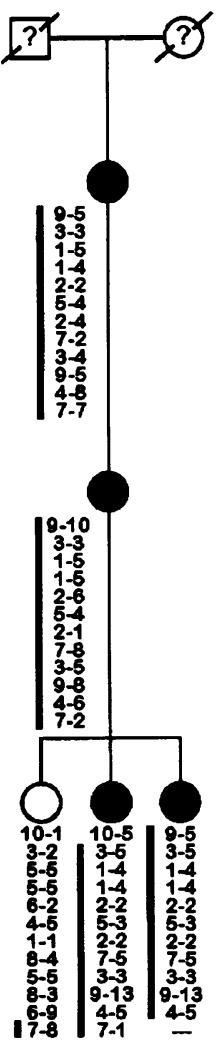

Figure 1 Pedigrees of the NCMD families $L, A$, and W. The marker loci analysed in the study are given in the order 6cen to 6qter (top to bottom). The phase known disease haplotypes in each family are indicated by a bar.

Table 2 Allelic association for 6q14-q16.2 marker loci on normal and NCMD/CAPED chromosomes

\begin{tabular}{|c|c|c|c|c|c|c|c|c|c|c|}
\hline \multirow[b]{2}{*}{ Locus } & \multicolumn{10}{|c|}{ Allele No } \\
\hline & 1 & 2 & 3 & 4 & 5 & 6 & 7 & 8 & 9 & 10 \\
\hline $\begin{array}{l}\text { D6S249 } \\
\text { Size (bp) }\end{array}$ & 146 & 148 & 152 & 156 & 158 & 160 & 162 & 164 & 一 & - \\
\hline $\begin{array}{l}\text { Frequency (\%) } \\
\text { Control* }^{\star}\end{array}$ & 2.0 & 68.0 & 1.0 & 15.0 & 1.0 & 2.0 & 10.0 & 1.0 & - & - \\
\hline $\begin{array}{l}\text { Affected } \\
\text { D6S1716 }\end{array}$ & 0 & 66.7 & 0 & 0 & 0 & 0 & 33.3 & 0 & - & - \\
\hline $\begin{array}{l}\text { Size (bp) } \\
\text { Frequency (\%) }\end{array}$ & 199 & 201 & 203 & 205 & 207 & 209 & 211 & - & - & - \\
\hline Control $(n=62) \dagger$ & $\begin{array}{l}3.3 \\
0\end{array}$ & 3.3 & $\begin{array}{l}26.2 \\
0\end{array}$ & $\begin{array}{l}34.3 \\
0\end{array}$ & $\begin{array}{l}23.0 \\
100\end{array}$ & $\begin{array}{l}3.3 \\
0\end{array}$ & 1.6 & - & - & - \\
\hline D6S1717 & & & & & & & & & & \\
\hline $\begin{array}{l}\text { Size (bp) } \\
\text { Frequency (\%) }\end{array}$ & 112 & 114 & 116 & 118 & 120 & 122 & 124 & 126 & 128 & 132 \\
\hline $\begin{array}{l}\text { Control }(n=96) \dagger \\
\text { Affected }\end{array}$ & $\begin{array}{l}38.6 \\
0\end{array}$ & $\begin{array}{l}29.2 \\
100\end{array}$ & $\begin{array}{l}2.1 \\
0\end{array}$ & $\begin{array}{l}8.3 \\
0\end{array}$ & $\begin{array}{l}1.0 \\
0\end{array}$ & $\begin{array}{l}3.1 \\
0\end{array}$ & $\begin{array}{l}11.5 \\
0\end{array}$ & $\begin{array}{l}3.1 \\
0\end{array}$ & $\begin{array}{l}2.1 \\
0\end{array}$ & $\begin{array}{l}1.0 \\
0\end{array}$ \\
\hline $\begin{array}{l}\text { D6S475 } \\
\text { Size (bp) }\end{array}$ & 144 & 148 & 152 & 156 & 160 & 163 & 164 & 168 & 172 & 180 \\
\hline $\begin{array}{l}\text { Frequency }(\%) \\
\text { Control }(n=80) \dagger\end{array}$ & 2.6 & 9.2 & 9.2 & 15.8 & 27.7 & 2.6 & 15.8 & 10.5 & 6.6 & 0 \\
\hline $\begin{array}{l}\text { Affected } \\
\text { D6S1543 }\end{array}$ & 0 & 0 & 0 & 0 & 0 & 0 & 33.3 & 0 & 0 & 66.7 \\
\hline $\begin{array}{l}\text { Size (bp) } \\
\text { Frequency (\%) }\end{array}$ & 101 & 111 & 113 & 115 & 117 & 119 & 121 & 123 & 125 & - \\
\hline Control $(n=52) \dagger$ & 0 & 11.5 & 17.3 & 23.0 & 30.9 & 11.5 & 5.8 & 0 & 0 & - \\
\hline Affected & 0 & 0 & 33.3 & 66.7 & 0 & 0 & 0 & 0 & 0 & - \\
\hline
\end{tabular}

In family $\mathrm{L}$ (fig 1) affected members presented with multiple drusen-like deposits mostly in the macular area but extending also into the mid-periphery of the fundus. Visual function was normal in most patients, but in one eye of a 25 year old patient severe visual loss with visual acuity of 10/200 occurred because of disciform scarring resulting from choroidal neovascularisation. In addition, two elderly patients developed atrophy of the retinal pigment epithelium of one disc diameter in size in the area of central deposits accompanied by mild visual loss. Clinically all affected family members showed light irides and choroid. This was associated with prolonged dark adaptation and increased light sensitivity.

In family A nine out of 14 members in three generations were between the ages of 7 and 65 years and presented with clinical signs of NCMD. Central chorioretinal changes varied from non-confluent drusen-like deposits to disciform scar-like formations. In six affected members peripheral drusen were detected near the equator. Visual acuity ranged from 0.5 to 1.0 with no correlation with the degree of fundoscopic findings nor the age of the affected person. Microperimetry in a 36 year old family member with stage 2 disease ${ }^{2}$ and a visual acuity of 0.8 did not show any central defects and confirmed foveolar fixation.

The clinical phenotype of family $W$ has been described in detail elsewhere. ${ }^{13}$ There are six affected members in three generations who also present with normal visual function and a wide spectrum of severity of macular involvement ranging from granularity of the macula to severe staphylomatous macular lesions. In all affected patients, peripheral retinal drusen were observed, as described by Small. ${ }^{14}$ Since Lefler et $a l^{1}$ reported an ongoing process 


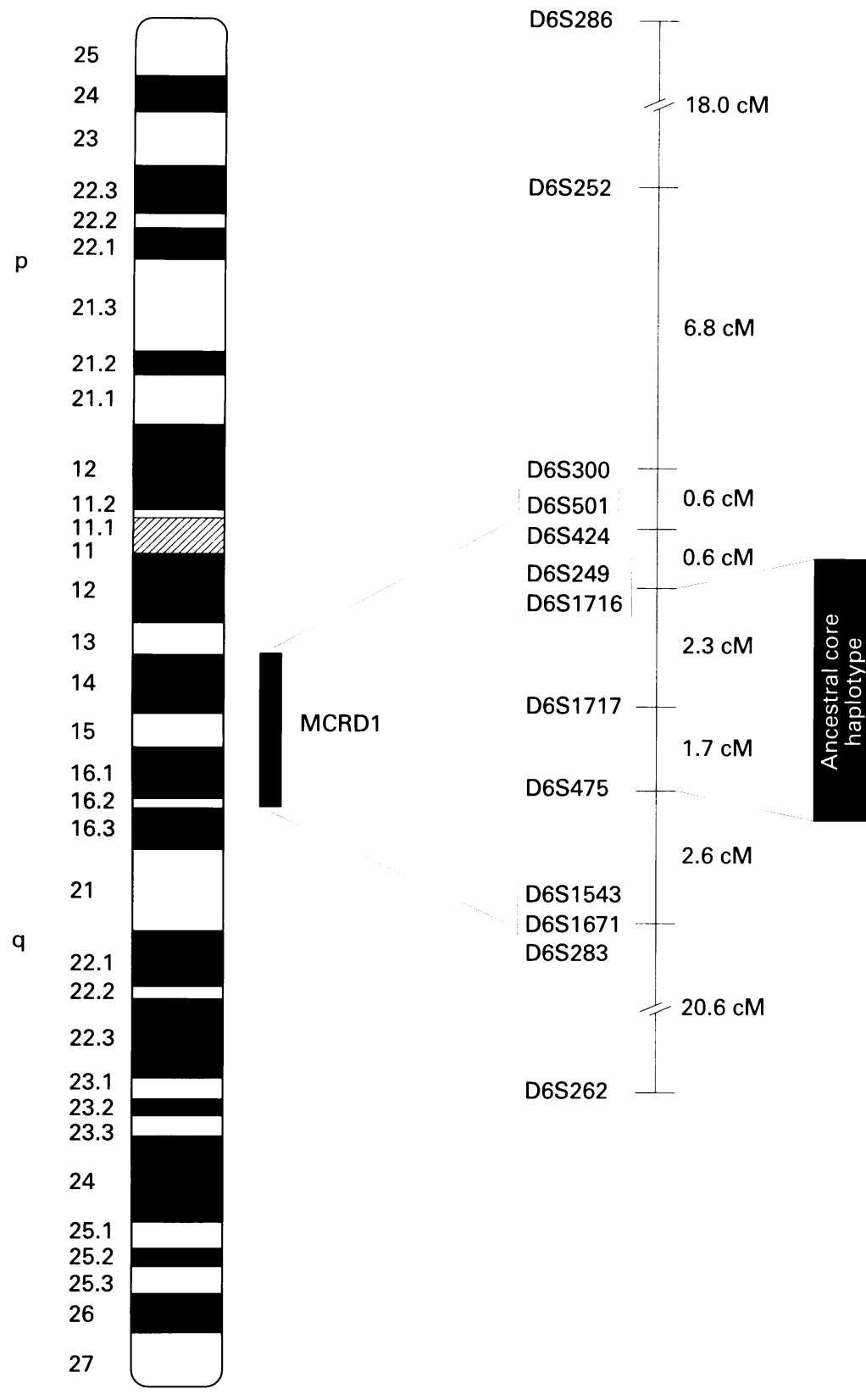

Chromosome 6

Figure 2 Chromosomal assignment of MCDR1 locus to 6q14-q16.2 and genetic map of marker loci used for genotyping the NCMD families. The order and genetic distances of loci were taken from the Center for Medical Genetics (http://genetics.mfldclin.edu). The core haplotype shared by all affected members of the three German NCMD families is indicated.

leading to deterioration of visual function in NCMD, the original diagnosis in 1992 was CAPED. However, over a period of more than 20 years the functional deficits were not progressive. Thus, the findings in family $\mathrm{W}$ are consistent with a diagnosis of NCMD.

Inspection of the three pedigrees strongly suggested complete penetrance of the disease phenotypes and an autosomal dominant mode of inheritance.

\section{GENOTYPING}

DNA was extracted from peripheral EDTA blood using standard techniques. ${ }^{15}$ Subjects were genotyped using the polymerase chain reaction (PCR) and highly polymorphic microsatellite markers at loci D6S249, D6S252, D6S262, D6S283, D6S286, D6S300, D6S475,
D6S501, D6S1543, D6S1671, D6S1716, and D6S1717. Primer sequences and allele frequencies were taken from Genethon (http:// www.genethon.fr), the Cooperative Human Linkage Center (http://www.chlc.org), and the Whitehead Institute Center for Genome Research (http://www-genome.wi.mit.edu). The order of markers and their genetic distances were adopted from the Center for Medical Genetics (http://genetics.mfldclin.edu). To ensure comparability between control chromosomes and the disease associated alleles at D6S249, D6S475, D6S1543, D6S1716, and D6S1717, allele sizes and their frequencies were analysed simultaneously on a single polyacrylamide gel run (table 2 ).

\section{LINKAGE ANALYSIS}

For pedigree drawing and data management Cyrillic version 2 (Cherwell Scientific, Oxford, UK) was used. An export function to a DOS compatible personal computer allowed the pairwise linkage analyses to be performed using the MLINK routine of the LINKAGE package version 5.1. ${ }^{16} \mathrm{NCMD} / \mathrm{CAPED}$ was analysed as an autosomal dominant trait. The penetrance was set at 1.0 and the frequency of the affected allele was estimated at 0.0001.

\section{HAPLOTYPE ANALYSIS}

The affected haplotypes were determined in the three families by segregation analysis. The probability $p_{c}$ that the three families share a common haplotype by chance was calculated using the Bayesian theorem with $p_{c}=1 /$ $(a b+a+b+1)$ where $a=$ probability for haplotype sharing by chance between the two families $A$ and $\mathrm{L}$ and $\mathrm{b}=$ probability for haplotype sharing by chance between the two families $A$ and W. The probability for haplotype sharing depends on the frequency of the respective haplotypes in the general population and was calculated as the product of the respective allele frequencies, as given in table 2 .

\section{Results}

GENOTYPING

A total of 24 affected and 14 unaffected subjects belonging to the three generation families $\mathrm{L}, \mathrm{A}$, and $\mathrm{W}$ were genotyped at 12 marker loci from chromosome 6q14-q16.2 (fig 1). For each family a phase known haplotype segregating with the disease phenotype was constructed. Several recombination events were observed involving the most proximal and most distal markers, D6S286 and D6S262, respectively (fig 1). Based on established linkage maps and previous results on NCMD mapping, ${ }^{6} \mathrm{D} 6 \mathrm{~S} 286$ and D6S262 should flank the MCDR1 locus at genetic distances of approximately 21 and $18 \mathrm{cM}$, respectively (fig 2 ). In contrast, the remaining 10 markers used in the present study together encompass a genetic distance of about $15 \mathrm{cM}$ and should be closely linked to the disease locus. Thus, the recombination events observed between the disease and the markers at D6S286 and D6S262 are in agreement with the known genetic distances and the location of the established MCDR1 gene locus. 
Table 3 Disease associated haplotypes segregating with NCMD/CAPED

\begin{tabular}{llll}
\hline & \multicolumn{3}{l}{ Disease associated haplotype } \\
\cline { 2 - 4 } Locus & Family $L$ & Family $A$ & Family $W$ \\
\hline D6S286 & 2 & 10 & 9 \\
D6S252 & 3 & 3 & 3 \\
D6S300 & 6 & 7 & 1 \\
D6S501 & 4 & 2 & 1 \\
D6S249 & 7 & 2 & 2 \\
D6S1716 & 5 & 5 & 5 \\
D6S1717 & 2 & 2 & 2 \\
D6S475 & 10 & 10 & 7 \\
D6S1543 & 4 & 4 & 3 \\
D6S1671 & 8 & 5 & 9 \\
D6S283 & 2 & 4 & 4 \\
D6S262 & 2 & 7 & 7 \\
\hline
\end{tabular}

TWO POINT LINKAGE ANALYSES

Two point lod scores at standard recombination fractions $\theta$ were calculated for NCMD versus the microsatellite markers from 6q14q16.2 using the genotyping data generated (fig 1). The results are summarised in table 1 . The combined lod scores for the NCMD families show significant linkage between the MCDR1 locus and all markers tested, with the exception of DNA markers at D6S286 and D6S262 which resulted in combined lod scores of $\mathrm{Zmax}=1.76$ and 0.37 at recombination fractions $\theta=0.15$ and 0.34 , respectively. The highest combined two point lod score of $Z \max =8.42$ at zero recombination fraction $(\theta=0.00)$ was observed at locus D6S475 (table 1).

ALLELIC AND HAPLOTYPE ASSOCIATION STUDIES For each marker locus the disease associated alleles were determined and the haplotypes segregating with NCMD in each family constructed (fig 1, table 3 ). Close inspection of the disease associated alleles showed an excess of allele sharing between affected subjects of the three families at five marker loci (D6S249, D6S1716, D6S1717, D6S475, and D6S1543). The absolute allele sizes and frequencies of these loci were determined in unrelated controls of German origin and compared to the NCMD associated alleles (table 2). At locus D6S249 the disease phenotypes were associated with common alleles 2 or 7 . In contrast, at locus D6S1716, allele 5 was present in $3 / 3$ (100\%) NCMD chromosomes versus $23.0 \%$ in normal chromosomes (table 2). Similarly, allele 2 at locus D6S1717 was associated with the disease chromosome in each family and was present in $29.2 \%$ of control chromosomes. Strikingly, allele 10 at locus D6S475 was associated with NCMD in families $L$ and $A$ but was not found in 80 control chromosomes. Also, at locus D6S1543 mapping $2.6 \mathrm{cM}$ distal to D6S475, affected subjects in families $L$ and $A$ shared the common allele 4 that was present in $23 \%$ of normal control chromosomes (table 2 ).

Assuming the loci order D6S249, D6S1716, D6S1717, D6S475, D6S1543 (Center for Medical Genetics; http://genetics.mfldclin.edu), a disease associated haplotype for each family was constructed. The disease haplotype 5-210-4 (at loci D6S1716, D6S1717, D6S475, and D6S1543) spanning approximately $6.6 \mathrm{cM}$ was shared between families $\mathrm{L}$ and $\mathrm{A}$ whereas families $\mathrm{A}$ and $\mathrm{W}$ had the disease haplotype 2-5-2 (at loci D6S249, D6S1716, and D6S1717) in common (fig 2, table 3). Assuming linkage equilibrium and using the allele frequencies as given in table 2 the probability of observing haplotype 5-2-10-4 in the general population is $0.230 \times 0.292 \times 0.001 \times$ $0.230=1.5 \times 10^{-4}$. Similarly, the probability of the disease haplotype $2-5-2$ in the normal population is $4.6 \times 10^{-2}$. Using the Bayesian theorem $1 /(a b+a+b+1)$ (see Methods) the probability that the three families share the overlapping haplotype 5-2 at loci D6S1716D6S 1717 by descent is 0.955 .

\section{Discussion}

While meiotic mapping is a common approach to refining a disease locus the analysis of individual recombination events may in some instances lead to ambiguous interpretations. One source of error may stem from misdiagnosis of a crucial family member. Moreover, the simplest interpretation of the data generated usually includes the assumption of single recombination events. However, more complex rearrangements such as double recombinations or gene conversion events may occur and consequently give rise to incorrect conclusions. In addition, a specific genetic disease may be rare in a given population and the number of informative meioses in affected subjects may be limited as may be the informativeness of tightly linked DNA markers in a recombinant subject. In these cases the genetic mapping of a disease locus often does not give the necessary accuracy required for positional cloning approaches. It is, therefore, desirable to have a robust and independent source of information to narrow the location of a specific disease gene.

The analysis of allelic or haplotype association is based on population rather than individual studies. ${ }^{17}$ Its principle and great potential for human genetics was first indicated in the context of sickle cell anaemia. ${ }^{18}$ The simple strategy includes the comparison of allele frequencies in a random group of affected subjects with those of a normal control population. Both the lack of genetic heterogeneity and a low new mutation rate is bound to increase the power of detection of allelic/haplotype associations and has allowed this approach to be applied successfully to refine the location of many important disease genes, such as cystic fibrosis, ${ }^{10}$ Huntington's disease, ${ }^{11}$ or myotonic dystrophy. ${ }^{12}$ In principle, one can assume an inverse correlation between the time of the mutational event and the extent of the physical region that is conserved around the disease gene. The more recent the origin of a mutation the larger the chromosomal region associated with the defective gene. Thus, the detection of non-random allelic association is bound to provide a high resolution approach for the precise mapping of a disease locus.

North Carolina macular dystrophy was originally desribed in a single large North American family that could be traced back to a founder from Ireland. ${ }^{5}$ Since then, additional families from various ethnic and geographical 
regions have been identified including those from England, France, Spain, Belize, and Mexico. ${ }^{67}$ In addition, extensive genealogical studies showed that central areolar pigment epithelial dystrophy (CAPED), originally believed to be a distinct disease entity, in fact occurred in separate branches of the North American NCMD family. Thus, today, the two disorders are considered a single disease entity with highly variable expressivity. ${ }^{5}$ So far, NCMD has not been reported to occur in people of German descent. Moreover, although an earlier report described a three generation family of German origin segregating the CAPED phenotype, ${ }^{13}$ the chromosomal location of the underlying gene defect and its relationship to NCMD still remains unclear. Our results now show that NCMD in the two German pedigrees is significantly linked to the known MCDR1 locus on chromosome 6q1416.2 lending further support for the genetic homogeneity of this condition. Similarly, the German CAPED family also shows linkage to the MCDR1 locus confirming previous findings of allelism of these two conditions. ${ }^{5}$

As NCMD is an extremely rare disorder in Germany, we reasoned that the three German families may descend from a single ancestral founder. Indeed, genotyping identified an allele at locus D6S475 which is rare in the general population but segregating with the disease in two of our three NCMD families. Moreover, extended analyses identified excess allele and haplotype sharing between NCMD and additional marker loci tightly linked to D6S475. Accordingly, the NCMD haplotype 2-5-2-10-4 (D6S249 - D6S1716 - D6S1717 - D6S475 D6S1543) segregating in family A was shared at loci D6S1716, D6S1717, D6S475, and D6S1543 with affected subjects in family $L$. The shared haplotype extends over at least 6.6 $\mathrm{cM}$ suggesting a more recent link between the two NCMD families. In contrast, the affected chromosomes of family W shared alleles 2-5-2 at loci D6S249, D6S1716, and D6S1717 with affected chromosomes of family A, spanning a genetic distance of only approximately $2.3 \mathrm{cM}$, thus indicating a more ancient separation of the two pedigrees. Our statistical calculations provide evidence at the $95 \%$ confidence level that the haplotype sharing of the German NCMD chromosomes is not the result of a chance event but rather an indication of identity by descent owing to an ancestral founder. If correct, haplotype 5-2 (D6S1716-D6S1717) represents the core haplotype probably harbouring the MCDR1 locus, thus narrowing the critical region to a $4.0 \mathrm{cM}$ interval flanked by D6S249 and D6S475 (fig 2). It is noted that additional highly polymorphic marker loci within or close to this interval are required and should be analysed to delineate further the chromosomal region of the core haplotype. Nevertheless, our approach shows the potential for the refinement of a disease locus by analysing small families that share a rare disease phenotype.

The authors wish to thank the families for their kind The sche Forschungsgemeinschaft (DFG).

1 Lefler WH, Wadsworth JAC, Sidbury JB. Hereditary macuar degeneration and aminoaciduria. Am 7 Ophthalmol 1971;71:224-30.

2 Small KW, Weber JL, Roses A, Lennon F, Vance JM, Pericak-Vance MA. North Carolina macular dystrophy is assigned to chromosome 6. Genomics 1992;13:681-5.

3 Fetkenhour CL, Gurney N, Dobbie GJ, Choromokos E. Central areolar pigment epithelial dystrophy. $A m \quad \dot{f}$ 976;8:745-53

4 Hermsen VM, Judisch GF. Central areolar pigment epithelial dystrophy. Ophthalmologica 1984;189:69-72.

5 Small KW, Hermsen V, Gurney N, Fetkenhour CL, Folk JC. North Carolina macular dystrophy and central areolar pigment epithelial dystrophy: one family, one disease. Arch Ophthalmol 1992;110:515-18.

6 Small KW, Puech B, Mullen L, Yelchits S. North Carolina macular dystrophy phenotype in France maps to the MCDR1 locus. Mol Vis 1997;3:1-6.

7 Small KW, Weber JL, Roses A, Pericak-Vance MA. North Carolina macular dystrophy (MCDR1). A review and refined mapping to 6q14-q12.2. Ophthal Paediatr Genet 1993;14:143-50

8 Holz FG, Evans K, Gregory CY, Bhattacharya S, Bird AC. Autosomal dominant macular dystrophy simulating North Carolina macular dystrophy. Arch Ophthalmol 1995;113. 178-84

9 Kelsell RE, Godley BF, Evans $\mathrm{K}$, et al. Localization of the gene for progressive bifocal chorioretinal atrophy 1653-6.

10 Kerem BS, Rommens JM, Buchanan JA, et al. Identification of the cystic fibrosis gene: genetic analysis. Science 1989;245:1073-80.

11 Theilmann J, Kanani S, Shiang $\mathrm{R}$, et al. Non-random association between alleles detected at D4S 95 and D4S 98 and the Huntington's disease gene. $\mathcal{J}$ Med Genet 1989;26: and the

12 Harley HG, Brook JD, Floyd J, et al. Detection of linkage disequilibrium between the myotonic dystrophy locus and a new polymorphic DNA marker. Am $\mathscr{f}$ Hum Genet 1991;49:68-75.

13 Käsmann B, Blankenagel A, Daus W. Die zentrale areoläre Pigmentepitheldystrophie. Ophthalmologe 1992;89:60-6.

14 Small KW. North Carolina macular dystrophy revisited. Ophthalmology 1989;96:1747-54.

5 Kunkel LM, Smith KD, Boyer SH, et al. Analysis of human $Y$ chromosome specific reiterated DNA in chromosom variants. Proc Natl Acad Sci USA 1977;74:1245-9.

16 Lathrop GM, Lalouel JM, Julier C, Ott J. Multilocus linkage analysis in humans: detection of linkage and estimation of recombination. Am $\mathcal{f}$ Hum Genet 1985;37:482-98.

17 Lewontin RC, Kojima KI. The evolutionary dynamics of complex polymorphisms. Evolution 1960;14:458-72.

18 Kan YW, Dozy AM. Polymorphism of DNA sequence adjacent to human beta globin structural gene: relationship to sickle mutation. Proc Natl Acad Sci USA 1978;75:5631-5. 